\title{
A community-based randomized trial for the prevention and control of brucellosis among rural populations in Iran: application of the PRECEDE planning model
}

\author{
Leila Jahangiry ( $\nabla$ jahangiry@razi.tums.ac.ir) \\ Maryam Khazaee-Pool \\ Mazandaran University of Medical Sciences \\ Towhid Babazadeh \\ Tabriz University of Medical Sciences \\ Parvin Sarbakhsh \\ Tabriz University of Medical Sciences \\ Koen Ponnet \\ Universiteit Gent
}

Tabriz University of Medical Sciences https://orcid.org/0000-0002-0491-5764

\section{Research article}

Keywords: Brucellosis, Precede, infection disease, rural population

Posted Date: February 18th, 2020

DOI: https://doi.org/10.21203/rs.2.13991/v2

License: (c) (i) This work is licensed under a Creative Commons Attribution 4.0 International License.

Read Full License 


\section{Abstract}

Background: Brucellosis is one of the most frequently occurring zoonotic diseases of veterinary and a public health problem in developing countries. It affects human and animal health and has measurable effects on the productive and reproductive performance of livestock. Therefore, the main purpose of this study was to develop a community-based intervention program for brucellosis prevention and control. A two-arm parallel cluster randomized controlled trial investigated the effectiveness of the program over six months in a rural population in Ahar, East Azerbaijan, Iran. A total of 16 village health houses were randomly allocated to the intervention and the control groups (eight per arm), and 400 participants were recruited via household health records in the health houses. The PRECEDE model, which is an acronym for Predisposing, Reinforcing and Enabling Constructs in Educational Diagnosis and Evaluation, was used to design, implement, and evaluate the brucellosis prevention and control program. Knowledge, attitudes, self-efficacy, social support, environmental enabling, and behavioral factors were measured at the baseline and the six-month follow-up. A generalized mixed effects model was used to analyze data.

Results: The mean ages (SD) of the intervention and control group respondents were 35.9 (11.87) and 37.28 (11.04) years, respectively. After the six-month intervention, significant between-group differences were found on all PRECEDE variables, adjusted for education, history of brucellosis, and family history of brucellosis.

Conclusion: There is a need to consolidate collaborative health and veterinary sector efforts, as well as increase regular vaccination practices and financial resources to support farmers willing to slaughter animals and/or offer slaughter facilities. The present study was able to demonstrate which educational and ecological factors influence behaviors and environments related to brucellosis and, as such, provide evidence of the effectiveness of interventions based on the PROCEDE model.

\section{Background}

Brucellosis is one of the most frequently occurring zoonotic diseases and is a public health priority in developing countries [1]. It has significant, measurable effects on the productive and reproductive performance of livestock [2], resulting in abortions, reduced productivity, and weak offspring. Therefore, brucellosis has major economic consequences for farmers, like loss of income. Brucellosis is transmitted to humans through direct contact with infected animals or the consumption of unpasteurized dairy products and may lead to serious morbidity with severe complications [3]. Brucellosis is one of seven neglected zoonotic diseases that continue to present major public health challenges due to the physical suffering and reduced financial abilities of those who are infected [4].

Although major progress has been made in brucellosis control and elimination in many countries, the incidence of human and animal brucellosis is still high [5]. Iran is one of the top five countries in the world with a high incidence of human brucellosis, with a prevalence ranging from approximately $0.5 \%$ to $10.9 \%$ [6]. The highest risk areas in Iran are in the East Azerbaijan province [7]. Brucellosis causes a persistent 
infection in domesticated animals, which is frequently transmitted to the human population [8]. The infection is transmitted to people who consume infected milk or cheese products, as well as via inhalation or animal contact [9].

Several factors account for the failure of brucellosis control plans. For livestock, these include inadequate attention to livestock health, poor quality of veterinary services, insufficient financial resources to curtail brucellosis, and infrequent animal vaccinations. For humans, the factors include eating habits (e.g., using homemade cheese without boiling of milk and other unpasteurized products), the consumption of dairy products [10], social and cultural customs, and socioeconomic status [11, 12].

A review of the literature [13] revealed that the control of neglected brucellosis requires integrated, collaborative actions from the public and veterinary health sectors, along with political support and consultations from other sectors and related organizations, especially on a regional scale. Tackling the problem of so-called neglect in relation to brucellosis requires high-level advocacy [13, 14].

Furthermore, it is necessary to identify all factors affecting the dissemination of brucellosis. To elucidate such factors, we used the PRECEDE-PROCEED model, which is an acronym for Predisposing, Reinforcing and Enabling Constructs in Educational Diagnosis and Evaluation, as a framework for planning and program evaluation. According to Green and Kreuter, who developed this model in the 1970s [15], in order to modify a behavior, the individual should not be the only target; rather, the entire surrounding environment and the factors affecting the individual's behavior should be considered. The model consists of educational, ecological, and behavioral assessments. The educational and ecological assessments address the following three factors: predisposing factors, enabling factors, and reinforcing factors $[15$, 16].

In sum, the main purpose of this study was to examine a community-based intervention, consisting of an educational program and an advocacy initiative, in terms of its effectiveness in the prevention and control of brucellosis.

\section{Methods}

\section{Trial design}

A two-arm parallel cluster randomized controlled trial was used to examine the effectiveness of a community-based brucellosis prevention program over six months in a rural population in Ahar, East Azerbaijan, Iran. The initial baseline assessment was conducted in July 2016, and the post-intervention assessment was performed six months after the baseline measurements were taken.

The high incidence of brucellosis in the rural areas of Ahar (31-41 cases per 100,000) [7] and the crucial need for a community-based brucellosis prevention program [17] led to its selection as the study setting. Due to the strong relationships among neighboring households in rural communities, it was not possible to assign participants to the same group. Therefore, we performed a stratified randomized controlled trial 
using rural health houses as the units of randomization. Health houses are located in rural areas, far away from health centers [17].

\section{Recruitment and sampling design}

In total, 16 health houses (one per village) with a high prevalence of brucellosis during the prior two years were selected for the recruitment of participants. Figure 1 shows the study flow chart. Participants from rural communities at high risk for brucellosis were randomly recruited using household health records in the rural health houses. The inclusion criteria were as follows: (a)

participant had to be 15 years of age or older and (b) living in the villages for at least six months after enrollment. People who were unwilling to provide consent for data collection and employees in the health centers or the veterinary office of Ahar County were excluded from the study.

A multi-stage random sampling method was used to select villages in the county. Ahar was stratified into four regions: north, south, east, and west. Two health centers were randomly selected from each region, and eight health houses (two from each region) with a high prevalence of brucellosis during the prior two years [7] were selected from each center. In total, 400 participants were recruited, and the number of participants selected from each health house was based on the proportion of the population it covered.

Randomization was carried out after the baseline measurements were taken. The 16 selected health houses were randomly allocated into eight intervention and eight control groups (arms) using permuted blocks randomization (PBD) to guarantee balance in the number of the units allocated to each arm. The randomization sequence was created manually by a biostatistician using Microsoft Excel software [Excel command for random block sizes column: =rand()] to assign the health houses to the study arms using a 1:1 allocation ratio with block size of four. A colleague not connected to the study performed equal group random allocation.

The participants were recruited by an independent researcher using computer-generated random number schedules from recorded lists of the household health files at the health houses. Trained research assistants gathered the baseline measurements while group allocation concealment was implemented. The participants were also blinded to their group assignments.

\section{Model for program planning}

The PRECEDE-PROCEED model [18] was used for the design, implementation, and evaluation of the brucellosis prevention and control program. The model includes nine phases based on assessments (PRECEDE), which should be made before planning a health intervention, and an evaluation (PROCEED) to enable the measurement of the effectiveness of the intervention at each stage of implementation, as well as the immediate and long-term effects (see Figure 2).

The priority targets for the intervention were established in each phase of the assessment based on the importance and changeability of specific behavioral and ecological factors in determining brucellosis 
outcomes (phases 1-5). Specifically, the assessment process focused on the seven behavioral and six ecological highest-priority factors (See Table 1), and the evaluation (phases 7-9) tracked the impact of the intervention on these factors.

\section{Phase 1: Social assessment}

Phase 1 of the PRECEDE-PROCEED model commenced by assessing the goals of the intervention. Diagnostic activities were performed to gather data to assess the health of the target population and identify the appropriate outcomes of the intervention.

\section{Phases 2 and 3: Epidemiological, behavioral, and environmental assessments}

We conducted an extensive literature review and informal discussions with selected key informants and health care staff from the Ahar Communicable Diseases Office, the Ahar Agriculture Jihad Office, and the Veterinary Office of Ahar County. These activities resulted in the identification of the issues affecting brucellosis prevalence, the steps that could be taken to reduce the impact of the disease, and the changes needed to prevent brucellosis. Using this information, the most significant behavioral and ecological risk factors for the intervention were determined based on their importance and changeability, resulting the selection of the seven behavioral and six ecological highest-priority factors, as noted above (See Table 1).

\section{Phase 4: Educational and ecological assessments}

This phase helped determine which intervention factors, if modified, would most likely result in behavior changes. These factors, classified as predisposing, enabling, and reinforcing factors, were identified through the literature review and key informant interviews with health workers, health care providers, experts on the surveillance and control of brucellosis in health centers, a veterinary specialist, and experts from agriculture organizations working on brucellosis in Ahar.

The results of this process were recently documented [18]. Briefly, a standardized, structured questionnaire was used to gather information from the target population about potential routes of transmission to humans and practices for dealing with aborted animal fetuses and for processing and consuming milk and dairy products. This questionnaire included five parts, addressing the predisposing, reinforcing, enabling, environmental, and behavioral factors. The first part focused on predisposing factors that provide a reason or motivation to perform a behavior, including knowledge, attitudes, and self-efficacy about the prevention, transmission, and control of brucellosis. The knowledge section included 11 items that measured rural population awareness and understanding about the causes, modes of transmission, and protective behaviors of brucellosis. The attitudes were measured using a 15item five-point Likert scale (strongly agree, agree, do not know, disagree, and strongly disagree). The selfefficacy section contained seven items with five-point Likert-type responses (very uncertain, uncertain, do not know, certain, and very certain). This section assessed the confidence of the participants in their ability to practice protective behaviors against brucellosis. 
The second part of the questionnaire focused on reinforcing factors that encourage and support certain behaviors due to social support, rewards, and praise, such as encouragement from family members or friends to take preventive measures against brucellosis. The prime sources of reinforcement identified were positive feedback and advice from family, friends, and health workers. Six items were used to assess how encouraging behaviors could be repeated and sustained by family members or friends.

The third part assessed enabling factors that allow people to act based on financial support, resources, assistance, and services. This part measured access to materials and financial and educational resources, including access to personal protective equipment, such as gloves and masks; financial support for the renovation of barns and buildings; and veterinary services supporting regular animal vaccinations against brucellosis.

The fourth part, assessed environmental factors, including characteristics of the environment that facilitate the development of behaviors or the attainment of resources required for protection from brucellosis. This part examined environmental safety practices related to brucellosis transmission vehicles using various direct and indirect measures targeted at reducing the risk of brucellosis infection and creating protective measures for the environment (e.g., wearing protective equipment, like gloves and masks, before going to the barn).

Finally, the fifth part looked at behavioral factors, which evaluated using nine items, including working with pastoral livestock, regularly vaccinating animals against brucellosis, consuming pasteurized dairy products on a regular basis, and wearing protective clothes while working in barns.

\section{Phases 5 and 6: Administrative and policy assessments and intervention}

The predisposing, enabling, and reinforcing factors that influence behavior were analyzed using the results from the assessments in phase 3 . Then, the appropriate strategies and interventions were matched with high-priority project changes according to the policies, resources, and organizational situations.

First, the enabling factors - which were considered the highest priority factors in this phase-were addressed, which required coordinated efforts and intersectional collaboration between local public health organizations, agricultural organizations, and veterinary organizations. The specific activities included continuously training health workers on brucellosis prevention, providing adequate resources for restoring and renovating barns, providing farmers with access to disinfectants and training in the proper use of those disinfectants, and compensating farmers whose animals died due to brucellosis.

Second, to address the predisposing factors, the knowledge, attitudes, and self-efficacy of the participants were promoted through the design and implementation of educational interventions, which were tailored using demographic variables. Third, the activities related to the reinforcing factors included encouraging more people to properly dispose of animal waste, giving information about how to bury aborted animal fetuses, and supporting regular animal vaccinations against brucellosis. 
In addition, we selected an advocacy strategy in order to promote policy changes and prevention measures that would reduce the prevalence of brucellosis in Ahar. Specifically, the goal of the advocacy initiative was to decrease the prevalence of brucellosis by $10 \%$ and increase HRQOL, in cooperation with the health centers and veterinary and agricultural organizations, by the end of 2016 .

The relevant stakeholders included anyone who would gain or lose from reaching the goal set for our advocacy efforts. We identified stakeholders through informal interviews and consultations with related organizations. The stakeholders were categorized into four groups: beneficiaries (farmers, household women, the Ahar primary health care network, and veterinary organizations), partners (the Ahar primary health care network, farmers, and veterinary and agricultural organizations), decision makers (the Ahar primary health care network, farmers, and veterinary and agricultural organizations), and adversaries (e.g. washing udders properly before milking). The advocacy approaches and persuasion techniques are described in Table 1.

For the advocacy initiative, activities included integrating veterinary and public health campaigns to increase public awareness of brucellosis and provide information about ways in which people could reduce the risk of infection. Close cooperation and coordination between all partners was crucial to success.

\section{Measurement tools}

The following demographic data was collected from all participants: gender, age, marital status, educational qualifications, job, history of brucellosis, and family history of the disease. As described above, a standardized, structured questionnaire, which included five parts (covering predisposing, reinforcing, enabling, environmental, and behavioral factors related to brucellosis), was used [18]. The questionnaires were filled out in writing and participants were also interviewed..

\section{Sample size}

The sample size was calculated based on a standard deviation increase in knowledge (6.8) [21], as this was one of the most important variables. As such, a study with a power of $90 \%$ at $5 \%$ significance level would need 185 participants in each group. Considering the risk of attrition, 200 participants per group were sought. The number of participants selected from each health house was based on the proportion of the population it covered.

\section{Statistical analysis}

The characteristics of the participants were summarized as numbers, percentages, or means with standard deviations, where appropriate. If the continuous variables were not normally distributed, appropriate transformations were performed to achieve normal distribution.

A generalized mixed effects-model was used to analyze the data. This model used cluster randomization

to incorporate random effects in order to reflect correlations among the observations of the members of 
the same health house. According to the distribution of our outcomes, the appropriate distribution and link functions were selected. For all parameters, $95 \%$ confidence intervals were defined, and two-sided $p$ values of less than 0.05 were considered statistically significant. All analyses were performed with the Statistical Package for the Social Sciences (SPSS) version 23 (SPSS Inc., Chicago, IL).

\section{Results}

Demographic characteristics of the participants

The demographic characteristics of the two groups are presented in Table 2. Of the 400 total respondents, the mean ages (SD) in the intervention and control groups were 35.9 (11.87) and 37.28 (11.04) years, respectively. In addition, $89 \%$ of the participants in the intervention group and $86.5 \%$ in the control group were married. Furthermore, $12.5 \%$ and $4.5 \%$ of the respondents in the intervention and control groups, respectively, had a history of brucellosis. The results also revealed that $19.5 \%$ of the participants in the intervention group and $10.5 \%$ in the control group had a family history of brucellosis. There were no significant differences between the two groups regarding demographic characteristics and the PRECEDE model-based variables except for history of brucellosis, family history of brucellosis, and education

Comparison of differences in the PRECEDE model variables at baseline and after six months

As presented in Table 3, there were significant differences in the PRECEDE model-based variables between the intervention and control groups after six months, adjusted for education, history of brucellosis, and family history of brucellosis. The generalized mixed effects model showed that there were significant differences between intervention and control groups for knowledge, attitudes, selfefficacy, social support, environmental, enabling and behavioral factors $(P<0.001)$.

\section{Discussion}

The current study described the planning process and results of an integrated intervention program for the prevention and control of brucellosis in a rural population in Ahar, East Azerbaijan, Iran. The prevention and control of brucellosis requires planning and the identification of all transmission routes of the disease in both humans and animals. The World Health Organization recommends focusing on education for all potentially exposed people [3]. In fact, there is a need to consolidate collaborative efforts from the health and veterinary sectors, as well as to strengthen regular vaccination practices and provide sufficient financial resources to compensate farmers willing to slaughter and/or offer slaughter facilities.

This diagnostic study of the educational and ecological factors influencing behaviors and environments related to the prevention and control of brucellosis identified where and how interventions can be most effective. By implementing interventions directed at these priorities (e.g., referring to veterinary organizations for regular animal vaccinations), including advocacy for policy changes, we expect that brucellosis incidence in human and animal populations will be reduced. 
Furthermore, our findings indicated that the knowledge levels of those in the intervention group increased significantly compared to the control group after six months. Therefore, the educational program was effective in increasing the knowledge levels of the participants in the intervention group. This is in line with a study performed in Khomeinshahr, Iran, using the PRECEDE model to prevent brucellosis infection among the rural population [21]. The findings of the present study are also consistent with a study by Liu et al. [22], as well as one performed by Jin et al. [23] on the reduction of brucellosis. Studies [22-25] also indicated that having low knowledge of zoonotic diseases may lead to their prevalence and problems controlling them [24]. For example, in a study conducted by Jedgal et al. [25] of people with pulmonary tuberculosis, a significant association was observed between knowledge and health promoting behaviors.

We found that the present intervention significantly increased the attitudes related to brucellosis preventive behaviors in the intervention group compared to the control group. These results are in line with those obtained by Ourogi et al. [21] and Liu et al. [22]. Therefore, attitudes should be considered as a main potential determinant for actions promoting health behaviors. As such, suitable measures should be taken to create positive attitudes towards health promoting behaviors [28].

The results of the current study also indicated that the mean self-efficacy score among the intervention group participants increased significantly following the intervention, which was consistent with the findings of a study conducted by Babaei et al. [26]. They confirmed that an educational program could improve perceived self-efficacy among rural people regarding brucellosis preventive behaviors. Beliefs in high personal self-efficacy toward health behaviors strongly decreased the perceived barriers of performing those behaviors. In line with our findings, Babaei et al. [27] reported that lower perceived barriers and higher perceived self-efficacy were associated with brucellosis preventive behaviors among stockbreeders. These findings suggest that considering self-efficacy while planning educational interventions could have an important role in changing behaviors.

A statistically significant difference was found in the environmental factor scores of the two groups before and after the intervention, which is consistent with the results of the study conducted by Orogi et al. [21]. Environmental factors, which are social and physical factors related to the individual and often beyond his or her personal control, can be modified to support certain behaviors or influence health outcomes [29].

A statistically significant difference was also observed in the enabling factors scores of the two groups before and after the intervention. Enabling factors are antecedents to behavioral or environmental change that allow a certain motivation or environmental policy to be realized [30].

\section{Conclusion}

The findings indicated that, after the intervention, significant increases were observed in the PRECEDEPROCEED model variables and the brucellosis preventive behaviors in the intervention group compared to the control group. Thus, the PRECEDE-PROCEED model could be applied to encourage individuals living 
in rural areas to practice brucellosis preventive activities, train them to perform environmental actions related to brucellosis prevention, and encourage them to develop personal beliefs in the importance of preventing brucellosis. Therefore, the PRECEED-PROCEED model may be considered as an applicable framework for educational interventions to increase brucellosis preventive behaviors.

\section{List Of Abbreviations}

SPSS: statistical package for social science software package

\section{Declarations}

Ethics approval and consent to participate

Informed written consent was obtained from all participants. Also, for participants under 16 years old, written informed consent was obtained from a parent or guardian. The study received ethical approval from the Ethics Committee of the Tabriz University of Medical Sciences (NO: IR. TBZMED.REC.1394.596).

Consent to publish

Not applicable.

Availability of data and materials

The data collection tools and datasets generated and/or analyzed during the current study are available from the corresponding author upon reasonable request.

Competing interest

The authors declare that they have no competing interest.

\section{Funding}

There is no funding source.

\section{Authors' contribution}

$\mathrm{LJ}$ is the supervisor of the study, design the study and wrote the draft. TB conduct requirements for study desgn. PS contributed to the study analysis. All authors read and approved the paper.

\section{Acknowledgments}

We acknowledge the contributions of Tabriz University of Medical Sciences, Tabriz, Iran for providing facilities to the study. Also, we express our deep appreciation and sincere thanks to Prof. Lawrence W. Green for his comments and suggestions on an earlier draft of the manuscript. 
Leila Jahangiry: Ph.D, Assistance Professor, · Health Education and Health Promotion Department, School of Public Health, Tabriz University of Medical Sciences, Tabriz, Iran

\section{References}

1. World Health Organisation: Brucellosis fact sheet, N173. Available at [http://www.who.int/zoonoses/diseases/brucellosis/en/]

2. Corbel MJ: Brucellosis: an overview. Emerging infectious diseases 1997, 3:213.

3. Corbel MJ: Brucellosis in humans and animals: World Health Organization; 2006.

4. Nicoletti P: Brucellosis: past, present and future. Prilozi 2010, 31:21-32.

5. Kafil HS, baha Hosseini S, Sohrabi M, Asgharzadeh M: Brucellosis: presence of zoonosis infection 3 500 years ago in North of Iran. Asian Pacific Journal of Tropical Disease 2014, 4:S684-S686.

6. Pappas G, Papadimitriou P, Akritidis N, Christou L, Tsianos EV: The new global map of human brucellosis. The Lancet infectious diseases 2006, 6 :91-99.

7. Esmaeili H: Brucellosis in Islamic republic of Iran. Journal of Medical Bacteriology 2015, 3:47-57.

8. Roushan MH, Mohrez M, Gangi SS, Amiri MS, Hajiahmadi M: Epidemiological features and clinical manifestations in $\mathbf{4 6 9}$ adult patients with brucellosis in Babol, Northern Iran. Epidemiology and infection 2004, 132:1109-1114.

9. Doganay M, Aygen B: Human brucellosis: an overview. International Journal of Infectious Diseases 2003, 7:173-182.

10. Kang'ethe EK, Ekuttan CE, Kimani VN, Kiragu MW: Investigations into the prevalence of bovine brucellosis and the risk factors that predispose humans to infection among urban dairy and nondairy farming households in Dagoretti Division, Nairobi, Kenya. East African medical journal 2007, 84:S96-100.

11. Shang $D$ : Progress in the study of prevention and control of Brucellosis in China in last $\mathbf{5 0}$ years. Zhonghua Liu Xing Bing Xue Za Zhi, 2000, 21:55-57.

12. Ragan $V$, Vroegindewey $G$, Babcock $S$ : International standards for brucellosis prevention and management. Revue scientifique et technique (International Office of Epizootics) 2013, 32:189-198.

13. Hotez PJ, Bottazzi ME, Franco-Paredes C, Ault SK, Periago MR: The neglected tropical diseases of Latin America and the Caribbean: a review of disease burden and distribution and a roadmap for control and elimination. PLoS Negl Trop Dis 2008, 2:e300.

14. McDermott J, Grace D, Zinsstag J: Economics of brucellosis impact and control in low-income countries. Revue scientifique et technique (International Office of Epizootics) 2013, 32:249-261.

15. Glanz K, Rimer BK, Viswanath K: Health behavior and health education: theory, research, and practice: John Wiley \& Sons, 2008.

16. Rimer BK, Glanz K: Theory at a glance: a guide for health promotion practice. 2005. 
17. Zeinali M, Shirzadi MR, Haj rasuliha H. National Guideline for Brucellosis Control. Second edition. Tehran: Raz Nahan Publishing; 2012.

18. Javanparast S, Baum F, Labonte R, Sanders D, Heidari G, Rezaie S: A policy review of the community health worker programme in Iran. Journal of public health policy 2011, 32:263-276.

19. Jahangiry L, Nadrian H, Mahdavi B, Allahverdipour H, Kousha A. Primary Development and Psychometric Properties of PRECEDE Model-based Scales for Brucellosis Prevention among an Iranian Rural Population, Arch Clin Infect Dis. 2017; 12(3):e62957.

20. Green LW, Kreuter MW: Health program planning: An educational and ecological approach. New York: McGraw-Hill, 2005.

21. Rohani C, Abedi HA, Langius A: The Iranian SF-12 Health Survey version 2 (SF-12v2): Factorial and convergent validity, internal Consistency and test-retest in a healthy sample. Iranian Rehabilitation Journal 2010, 8:4-14.

22. Oruogi M, Bayt Asghari A, Charkazi A, Jvaheri J: Survey on Effect of Health Education Intervention on Reduction of Brucellosis Incidence in Rural Areas of Khomein Based on PRECEDE Framework. Journal of Health 2012, 3:50-58.

23. Liu XL, Zhou YB, Liu XG. Knowledge, attitude and behaviors on brucellosis among occupational groups in western Liaoning province. Chinese Journal of Public Health 2009; 25: 1475-6.

24. JIN F, MA TB, HU XZ. The evaluation of intervention effect of Brucellosis in Hongsipu. Ningxia Medical Journal. 2012; 34:626-9.

25. Tebug S, Njunga GR, Chagunda MG, Mapemba JP, Awah-Ndukum J, Wiedemann S. Risk, knowledge and preventive measures of smallholder dairy farmers in northern Malawi with regard to zoonotic brucellosis and bovine tuberculosis. Journal of Veterinary Research, 2014. 81: p. 1-06.

26. Jedgal Kh, Zareban I, Alizadeh-Siuki H, Izadirad H. The Impact of Educational Intervention Based on Health Belief Model on Promoting Self-Care Behaviors in Patients with Smear-Positive Pulmonary TB. Journal of Health Education and Health Promotion Summer, 2014. 2: p. 143-152. [persian]

27. Babaei V, Garmaroodi G, Batebi A, Alipour D, Shahbaz M, Babazadeh T. The effectiveness of an educational intervention based on the health belief model in the empowerment of stockbreeders against high-risk behaviors associated with brucellosis. J Educ Community Health. 2014 Dec 15;1 :12-9.

28. Babaei V, Babazadeh T, Kiani A, Garmaroodi G, Batebi A. The Role of Effective Factors in Preventive Behaviors of Brucellosis in Stockbreeder of Charaoymaq County: A Health Belief Model. J Fasa Univ Med Sci. 2016; $5: 470-478$.

29. Saffari M, Amini N, Eftekhar Ardebili H, Mahmoudi M, Sanaeinasab H. Evaluation of an educational intervention based on PRECEDE PROCEED model toward lifestyle improvement among adolescents. Daneshvar Medicine. 2012; $19: 59-68$.

30. Glanz K, Rimer BK, Viswanath K. Health behavior and health education: theory, research, and practice. 2008: John Wiley \& Sons. 
31. Rodríguez C, Heredia OR, Fernández MM , González GG. Educational intervention to elevate the level of knowledge on brucellosis in workers exposed to risk: Camagüey municipality. AMC 2009; 13(3):112.

\section{Tables}

Table 1: High-priority behavioral and environmental factors based on importance and changeability

\begin{tabular}{|c|c|}
\hline \multirow{16}{*}{$\begin{array}{l}\text { Easy to } \\
\text { change }\end{array}$} & High importance for planning \\
\hline & Behavioral factors \\
\hline & 1. Boiling raw milk for five minutes before consumption \\
\hline & 2. Wearing gloves during barn work \\
\hline & 3. Washing udders properly before milking \\
\hline & 4. Vaccinating cattle during disease season \\
\hline & 5. Avoiding the use of fresh cheese and unpasteurized dairy products \\
\hline & 6. Disinfecting the sites of animal abortions \\
\hline & 7. Wearing a mask during barn work \\
\hline & Environmental factors \\
\hline & 1. obtaining vaccinations from the veterinary organization \\
\hline & $\begin{array}{l}\text { 2. Providing a trunk to carry animal waste for pepole who have worked with } \\
\text { mentioned animals }\end{array}$ \\
\hline & $\begin{array}{l}\text { 3. Diagnosing and slaughtering infected animals from the veterinary } \\
\text { organization }\end{array}$ \\
\hline & 4. Disposing animal waste in dumpsites located far from the village \\
\hline & $\begin{array}{l}\text { 5. Locating livestock away from human homes and not in close proximity } \\
\text { to farmers }\end{array}$ \\
\hline & $\begin{array}{l}\text { 6. Renovating barns and using building resources from agriculture } \\
\text { organizations }\end{array}$ \\
\hline \multirow{4}{*}{$\begin{array}{l}\text { Hardly } \\
\text { changed }\end{array}$} & \\
\hline & 1. Digging a hole for aborted fetuses, which is physically hard work \\
\hline & 2. Paying compensation for any infected animals that are culled \\
\hline & 3. Disinfecting barns (by the veterinary organization) \\
\hline
\end{tabular}

Table 2. Descriptive characteristics of the intervention and the control group participants 


\begin{tabular}{|c|c|c|c|c|}
\hline & & $\begin{array}{c}\text { Intervention } \\
(\mathrm{n}=200)\end{array}$ & $\begin{array}{c}\text { Control } \\
(\mathrm{n}=200)\end{array}$ & $\begin{array}{c}\text { p- } \\
\text { value }\end{array}$ \\
\hline Age $(n$ & SD) & $35.9(11.8)$ & 37.2 & 0.226 \\
\hline Gender n (\%) & Male & $95(47.5)$ & $94(47.3)$ & 0.271 \\
\hline & Female & $105(52.5)$ & $\begin{array}{l}106 \\
(52.7)\end{array}$ & \\
\hline Education & Illiterate & $20(10.0)$ & $15(7.5)$ & 0.023 \\
\hline & Elementary & $103(51.5)$ & $\begin{array}{l}123 \\
(61.5)\end{array}$ & \\
\hline & Secondary & $58(29.0)$ & $55(27.5)$ & \\
\hline & University & $21(10.5)$ & $7(3.5)$ & \\
\hline Marital status & Married & $178(89.0)$ & $\begin{array}{l}173 \\
(86.5)\end{array}$ & 0.325 \\
\hline & Single & $18(9.0)$ & $18(9.0)$ & \\
\hline & Widowed/divorced & $4(2.0)$ & $9(4.5)$ & \\
\hline Employment status & Farmer/agriculture & $55(27.5)$ & $63(31.5)$ & 0.603 \\
\hline & Self-employment & $32(16.0)$ & $37(18.5)$ & \\
\hline & Household & $101(50.5)$ & $91(45.5)$ & \\
\hline & Student & $12(6.0)$ & $9(4.5)$ & \\
\hline History of brucellosis & Yes & $25(12.5)$ & $9(4.5)$ & 0.004 \\
\hline & No & ? & ? & \\
\hline $\begin{array}{l}\text { Family history of } \\
\text { brucellosis }\end{array}$ & Yes & $39(19.5)$ & $21(10.5)$ & 0.012 \\
\hline & No & ? & ? & \\
\hline
\end{tabular}

Table 3. Comparison of PRECEDE model-based variables before and after the intervention in the intervention and the control groups

\begin{tabular}{|c|c|c|c|c|c|c|c|}
\hline & \multicolumn{3}{|c|}{ Intervention $(\mathrm{n}=200)$} & \multicolumn{3}{|c|}{ Control $(\mathrm{n}=200)$} & \multirow{2}{*}{$\begin{array}{c}\mathrm{p}- \\
\text { value* }\end{array}$} \\
\hline & Baseline & 6-months & p-value & Baseline & $\begin{array}{l}\text { 6- } \\
\text { months }\end{array}$ & p-value & \\
\hline owledge & $\begin{array}{l}12.3 \pm \\
1.1 \\
\end{array}$ & $13.8 \pm 0.38$ & $<0.001$ & $7.12 \pm 1.3$ & $6.82 \pm 1.3$ & $<0.001$ & $<0.001$ \\
\hline itudes & $51.1 \pm 4.7$ & $57.1 \pm 1.6$ & $<0.001$ & $\begin{array}{l}41.1 \\
+5.7\end{array}$ & $41.3 \pm 5.8$ & 0.009 & $<0.001$ \\
\hline f-efficacy & $27.6 \pm 5.4$ & $33.2 \pm 1.5$ & $<0.001$ & $24.3 \pm 3.6$ & $19.8 \pm 3.3$ & $<0.001$ & $<0.001$ \\
\hline cial support & $26.4 \pm 4$ & $34.7 \pm 2$ & $<0.001$ & $25.3 \pm 4.3$ & $\begin{array}{l}25.6 \pm \\
+4.9\end{array}$ & 0.122 & $<0.001$ \\
\hline $\begin{array}{l}\text { vironmental } \\
\text {;tors }\end{array}$ & $13.2 \pm 2.7$ & $17.2 \pm 1.8$ & $<0.001$ & $12.1 \pm 2.6$ & $12.3 \pm 2.8$ & 0.147 & $<0.001$ \\
\hline abling factors & $12.5 \pm 3$ & $11.7 \pm 1.6$ & $<0.001$ & $10.9 \pm 3.3$ & $18.9 \pm 3.3$ & $<0.001$ & $<0.001$ \\
\hline $\begin{array}{l}\text { havioral } \\
\text { :tors }\end{array}$ & $30 \pm 4.8$ & $39.7 \pm 1.8$ & $<0.001$ & $27.7 \pm 4.1$ & $27.7 \pm 4.1$ & 0.169 & $<0.001$ \\
\hline
\end{tabular}

p-value: Derived from the generalized mixed effects model and adjusted for education,* history of brucellosis, and family history of brucellosis 


\section{Additional File Information}

[File not included with this version.]

Title of data: SPIRIT 2013 checklist: Items to address in a clinical trial protocol

Description of data: Administrative information to address in a clinical trial protocol

File name:

Figures 


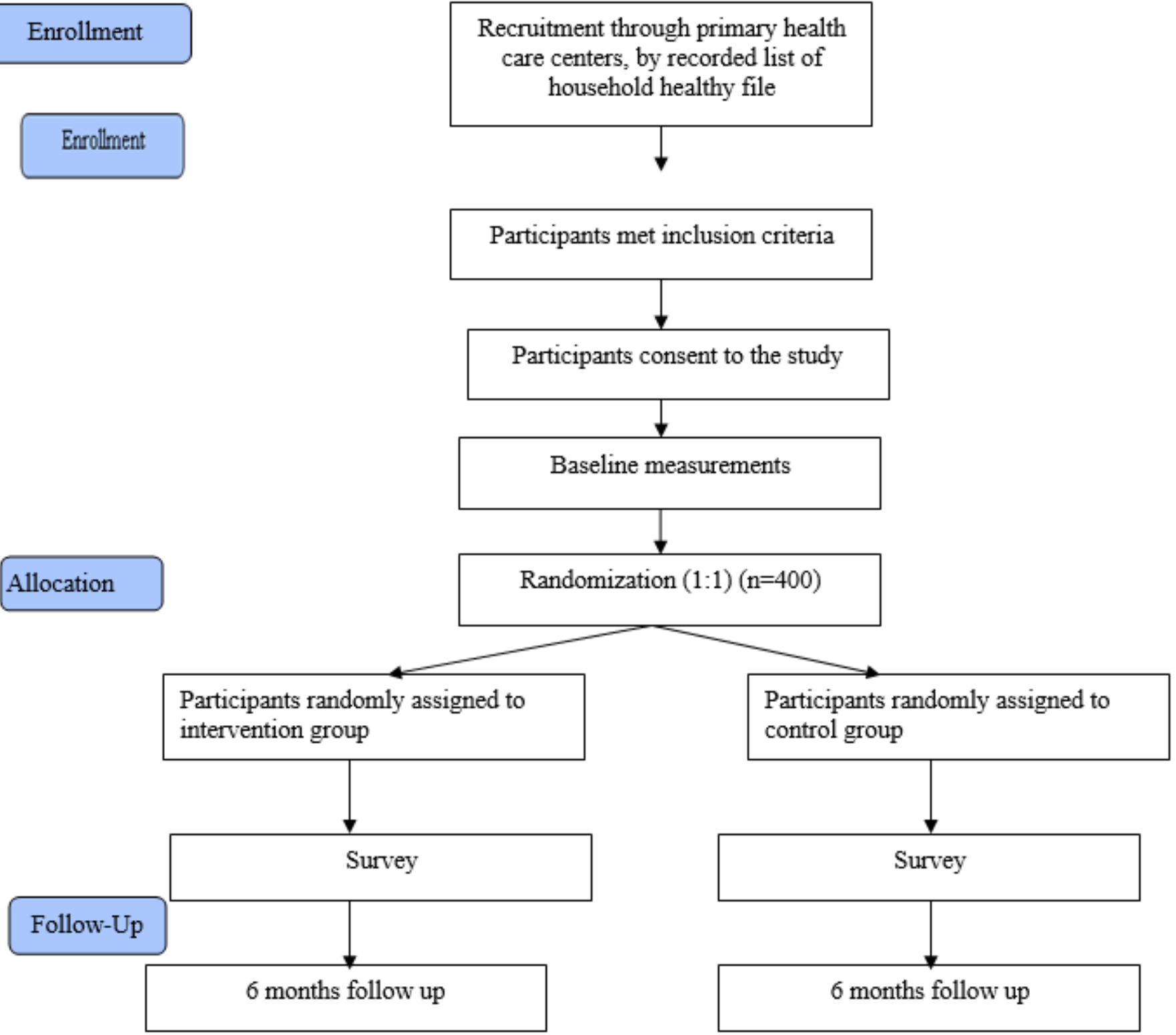

Analysis

Figure 1

The study flowchart 


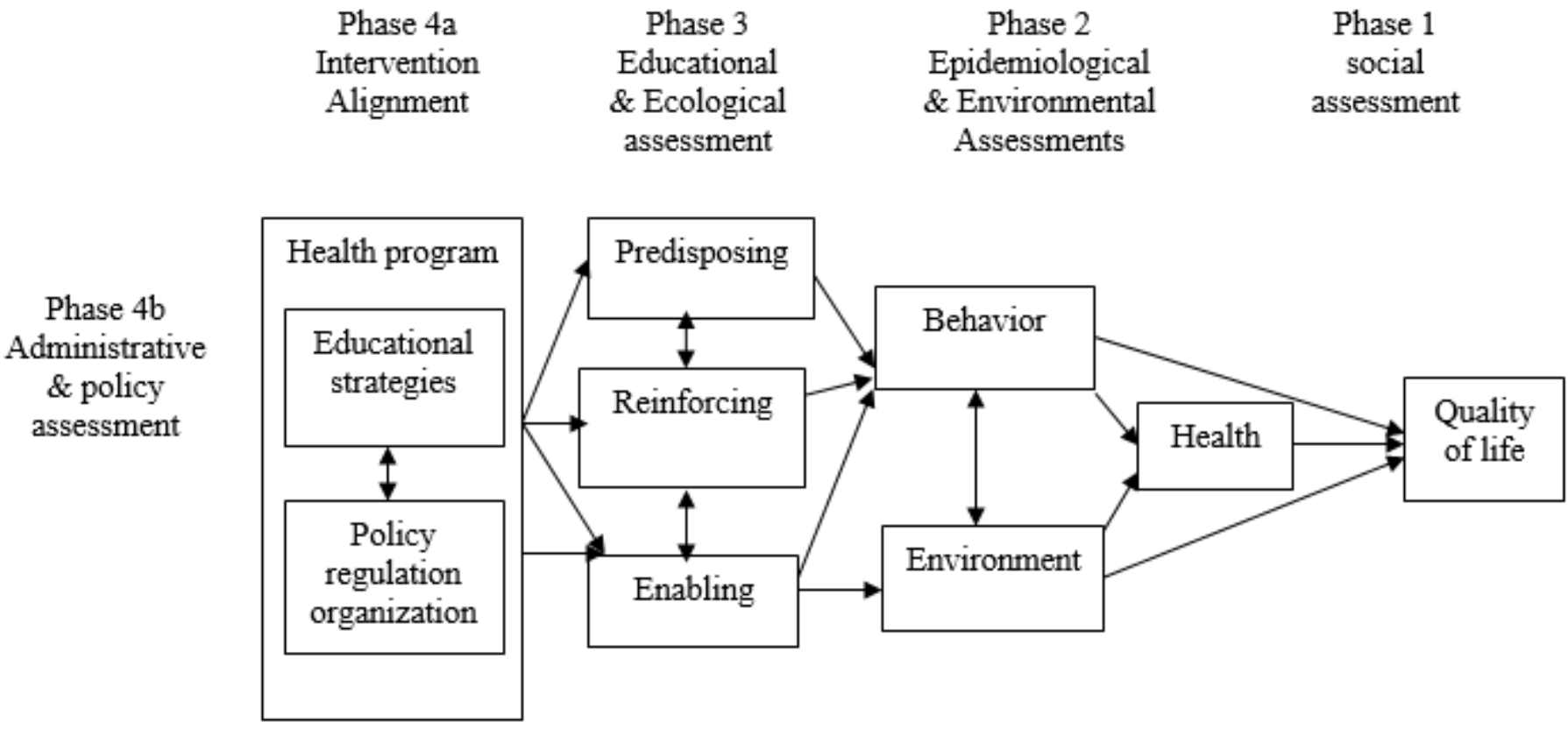

Predisposing factors: knowledge, attitude and self- efficacy

Reinforcing factors: social support

Enabling factors: access to material, financial and educational resources

Figure 2

The PRECEDE model 